City University of New York (CUNY) CUNY Academic Works

\title{
Librarianship presence in virtual worlds
}

Jenny M. Baum

New York Public Library

Kate Lyons

CUNY Hostos Community College

\section{How does access to this work benefit you? Let us know!}

More information about this work at: https://academicworks.cuny.edu/ho_pubs/6

Discover additional works at: https://academicworks.cuny.edu

This work is made publicly available by the City University of New York (CUNY).

Contact: AcademicWorks@cuny.edu 


\section{Handbook of Research on Practices and Outcomes in Virtual Worlds and Environments}

Harrison Hao Yang

State University of New York at Oswego, USA

Steve Chi-Yin Yuen

The University of Southern Mississippi, USA

Volume II 
Senior Editorial Director:

Kristin Klinger

Director of Book Publications:

Julia Mosemann

Editorial Director:

Lindsay Johnston

Acquisitions Editor:

Erika Carter

Development Editor:

Hannah Abelbeck

Production Editor:

Sean Woznicki

Typesetters:

Print Coordinator:

Jennifer Romanchak, Mike Brehm

Cover Design:

Jamie Snavely

Nick Newcomer

Published in the United States of America by

Information Science Reference (an imprint of IGI Global)

701 E. Chocolate Avenue

Hershey PA 17033

Tel: 717-533-8845

Fax: 717-533-8661

E-mail: cust@igi-global.com

Web site: http://www.igi-global.com

Copyright (C) 2012 by IGI Global. All rights reserved. No part of this publication may be reproduced, stored or distributed in any form or by any means, electronic or mechanical, including photocopying, without written permission from the publisher. Product or company names used in this set are for identification purposes only. Inclusion of the names of the products or companies does not indicate a claim of ownership by IGI Global of the trademark or registered trademark.

\section{Library of Congress Cataloging-in-Publication Data}

Handbook of research on practices and outcomes in virtual worlds and environments / Harrison Hao Yang and Steve Chi-Yin Yuen, editors.

p. $\mathrm{cm}$.

Includes bibliographical references and index.

Summary: "This book not only presents experienced professionals with the most recent and advanced developments in the field, but it also provides clear and comprehensive information for novice readers, introducing theoretical aspects and first-hand practices in virtual world development and use"--

Provided by publisher.

ISBN 978-1-60960-762-3 (hardcover) -- ISBN 978-1-60960-763-0 (ebook) -- ISBN 978-1-60960-764-7 (print \& perpetual access) 1. Shared virtual environments. 2. Internet in education. 3. Internet games. I. Yang, Harrison Hao, 1964- II. Yuen, Steve Chi-Yin, 1953-

QA76.76.I59H365 2011

004.67'8071--dc23

2011014614

British Cataloguing in Publication Data

A Cataloguing in Publication record for this book is available from the British Library.

All work contributed to this book is new, previously-unpublished material. The views expressed in this book are those of the authors, but not necessarily of the publisher. 


\title{
Chapter 20 Librarianship Presence in Virtual Worlds
}

\author{
Jenny Baum \\ New York Public Library, USA \\ Kate Lyons \\ Hostos Community College Library, USA
}

\begin{abstract}
Librarianship has stereotypically been about books, communities, and the connection between the two. With the emergence of new media and technology, the concept of books has expanded to include information of all types and in multiple formats: eBooks, DVDs, videogames, electronic databases, et cetera. Meanwhile, the idea of community has stayed the same. For example, public libraries primarily serve communities defined by geographic lines; academic libraries serve their campus communities. In non-profit, medical or corporate libraries, communities are defined by their organization's particular mission. However, now that virtual worlds are becoming mainstream, librarians are redefining community, just as they redefined books. With the emergence of virtual worlds, librarians are encountering virtual patrons, and communities defined by virtual lines that defy physical boundaries. This chapter discusses the librarians and organizations that are moving librarianship into virtual communities, as well as the first library initiatives in online worlds.
\end{abstract}

\section{INTRODUCTION}

In the "real" world, the field of librarianship is feeling the challenge of communities that consist of a plethora of users with access to information via the World Wide Web and other emerging technolo-

DOI: 10.4018/978-1-60960-762-3.ch020 gies, twenty four hours a day, seven days a week. In response, over the past decade, librarianship has undergone tremendous change. Library professionals evolved from having expertise primarily with traditional print-based resources to having a brand new skillset based on expertise with digital resources. Managing technology became a prerequisite for managing information resources, 
and librarians were suddenly poised to explore new technology, including Virtual Worlds. Most librarians consider it their mission to serve the information needs of their communities, and it is no great leap to see a community defined by a virtual space, rather than by geographic boundaries. As Greenhill(2008) shows, "more than 500 librarians have been experimenting with providing library services within Second Life" (p. 377). Moreover, according to Czarnecki (2008), "it is predicted in a recent report by Gartner Inc that " $80 \%$ of active internet users will be in a virtual world by the end of 2011" (p. 1). Librarians' colonization of virtual worlds is important both to virtual users, and to the field of librarianship. Librarians bring much needed services to these users, and at the same time, carve out a new way to serve the information needs of users who are surrounded by information all the time. The purpose of this chapter is to document and discuss major initiatives in the field of library science, that are taking place in, or related to virtual worlds.

This chapter is divided into four parts. This first is background information about librarianship and a short explanation of how librarians began exploring virtual worlds. The second part, "By, For And About Virtual Worlds: New Initiatives For A New Space" is comprised of initiatives that exist solely in a virtual world, and initiatives that exist solely for the purpose of managing or preserving virtual worlds. Included in this second section is a discussion about the following initiatives: Info Island, the Digital Preservation Project and Mystery Manor. This section also includes a general discussion about virtual library collections and Information Literacy. The third part of this chapter, "Extending Library Spaces Into Virtual Worlds: Reinventing Local" is comprised of virtual world initiatives that are extensions of their real life library services. Included in this section is a discussion of library programming in Second Life (SL), libraries that carve out informational spaces in virtual worlds, ISTE and other organizations that extend their services into Second Life, and finally, the use of virtual worlds by librarians for professional and social networking. The fourth, and final, part of the chapter describes future research directions. The chapter concludes with challenges librarians have faced in their new roles in virtual spaces.

\section{PART I: BACKGROUND}

Although the"shushing" librarian stamping books is iconical in the United States, the reality is multipronged career path, one that rarely involves a stamp pad. Librarian titles range from having everything to do with the community: outreach, public services, etc, to having everything to do with managing collections: cataloger, metadata specialist, archivist, serials librarian, to name a few. And of course, library managers might spend more time on budget or human resource issues than on traditional librarianship. Many libraries are divided into circulation, reference, media services and administrative areas. Public libraries often have separate rooms for adults, young adults and children. Over the recent few years that librarians have been exploring virtual worlds, they have initiated projects that reflect this diversity in career paths. Reference and information services, children's programs, collection development, archival work, virtual world preservation and myriad other librarianship-related projects can all be found in virtual worlds.

Additionally, librarians can be found in a few different virtual worlds, since Second Life has recently been a virtual hotbed of activity. In a chapter contributed to Virtual worlds, real libraries: Librarians and educators in second life and other multi-user virtual environments, Grover discusses how Second Life is one of many Multi-User Virtual Environments (MUVEs) that are making inroads in school, library and work settings, for children and adults. The chapter includes discussions about public librarians and school librarians who have also written about and 
experimented with youth-oriented virtual worlds, such as Club Penguin and Whyville. However, librarians should continue to make their presence known, since, as Stimpson (2009) writes, "The Second Life Library Project[...] lists over 120 libraries and library organizations within Second Life" (p. 13). Although 120 may sound like a lot, for a global enterprise like Second Life, there are still many aspects of libraries that could be represented. Second Life librarians have begun initiatives that center around traditional services such as information literacy, reference, youth services, outreach and library programs like book talks and book discussion groups, as well as initiatives that exist only in the virtual arena.

There are common benefits and challenges to working in virtual worlds, regardless of a librarian's specialty. For example, the way librarians can use virtual worlds to model real world behavior transcends their particular library discipline. Archivists, catalogers, public services librarians, to name just a few, all can appreciate the value of a staging environment for potential projects, a virtual petri dish, if you will. Many pioneering libraries and librarians have helped to grow Second Life and similar online environments to extend the kinds of positive changes that real-world libraries promote in their communities. Moreover, librarians have been there indirectly to report on unethical financial behaviors and assist with SL becoming a more global enterprise and directly to buttress SL professional conferencing and promote education and culture through virtual spaces. As a new frontier, SL provides the opportunity for all types of behavior, in addition to all types of personal presentation. In the Journal of Virtual Worlds Research, in the article "Order and Creativity in Virtual Worlds" authors Osbourne and Schiller (2009) examine ethics in MUVEs and behaviors that are constructive or destructive, either intentionally or unintentionally (p.5). While most libraries are not exactly hotbeds of unethical behaviors, it is important to remember that virtual worlds do not have the societal guidelines and control mechanisms that exist in the physical world. Also, since SL is international, societal norms may differ depending on the audience. The potential for commercial growth is certainly present in SL, and with it comes the potential for unethical financial behaviors. According to their blog, the "Second Life economy totals $\$ 567$ million US dollars in 2009 - 65\% growth over 2008 Gross Resident Earnings are \$55 million US Dollars in 2009 - 11\% growth over 2008". Regardless of a virtual librarian's role in Second Life, understanding the challenges and benefits of a nascent world, with all the kinks that come with change and fast growth, is crucial. Second Life is not just a game. Because Lindens (the virtual currency of Second Life) can reflect "real world" currency (One US dollar $=\$ 250$ Linden dollars and there are exchange rates for every country in the world), librarians (and other SLresidents) must understand that the stakes in Second Life may be higher than they anticipate, and users might have unexpected agendas.

Since SL is so new and unexplored, it has some unique problems and some real-world influenced problems, both important as case studies when creating libraries in virtual worlds and when deciding how to best serve MUVE users of libraries. According to Sidel (2008), SL suffered a collapse of its virtual banks that mirrored the subprime-mortgage mess of reality, due to ties to actual money through PayPal or credit cards (para. 1). Many educators and librarians might recognize this as an opportunity for a teachable moment in financial literacy, and it might lead a library to think twice before taking fines in Lindens, the virtual currency of SL. Moreover, the virtual environment of SL is skewed to reflect the United States and English since most players are from the U.S. As many libraries have already learned from their Web sites, though they may be intended to primarily serve patrons residing in the immediate geographic area, their resources may 
attract patrons from across the globe and, if possible, it helps to have reference desk hours and languages that serve as many as possible, perhaps through a 24 hour 7 days a week chat consortium with other libraries. As SL gains popularity, it will likely evolve to better reflect global interests. Linden Labs has run up against questions about how to handle the laws and regulations of different companies regarding money practices. In the case of gambling, they chose to disallow it, which also had consequences for the banks that had a stake in SL gambling investments.

Being a librarian working in Second Life is a double-edged sword, with both benefits and challenges. On the one hand, as Stimpson notes, libraries have traditionally employed "free stuff" as an outreach tool and virtual "free stuff" has the added benefit of being free, or nearly free, for the library to create and distribute. The price, for the most part, is simply the cost of design and code. Librarians are increasingly adept at technology, and many have art and design backgrounds. On the other hand, creating and designing attractive and functional items in virtual worlds, including Second Life, takes a time commitment as well as technology skills that cannot be taken for granted as part of most librarians' repertoires, at this point in time. Nevertheless, assuming a library is staff with workers with these skills, or assuming that a librarian in Second Life is motivated and has the time to learn, there is no cost. Unlike giveaways at library programs, or even the cost of cookies and coffee at a library event in the "real world," creating items in Second Life need not require a budget. Moreover, conducting outreach requires no travel since avatars are free to "teleport" wherever they like. Unlike the public librarian who might spend an hour traveling to a nearby nursing home, school or prison, geographic boundaries in virtual worlds clearly do not exist. A librarian on Second Life, for example, can present a booktalk to a class on Second Life, with absolutely no travel time. This is a huge benefit. And, unlike a conference call or email, which also unites people across geographic boundaries, Second Life, and some other virtual worlds, have a "real world" sort of feel. Because of the avatar experience, group presentations and meetings feel much more like in-person meetings, than they feel like conference calls or even chat room discussions.

Virtual worlds have an added benefit of accessibility. Wheelchair users need not worry about adjustable height tables, stairs or other physical boundaries. Avatars need not have crutches or canes. Users can converse with speech using microphones and speakers, or with text, which is especially appealing for users with special auditory needs. In addition to users with disabilities, the multitude of ways for users in Second Life to communicate is a boon for education, where students all have different learning styles and benefit from different learning venues.

Libraries and librarians are present in virtual worlds, and are helping to build them. Librarians are an important part of the history of virtual worlds, and librarians are working to preserve their unique society and culture. Discussing the presence of libraries in virtual worlds means capturing a truly important group in the development and popularization of virtual worlds. It also means bolstering the coverage of educational aspects of virtual worlds and helping to make them accessible to students. Some librarians, as well as some educators advocate for the use of games in education. To some extent, virtual worlds fall into their realm. However, virtual worlds, as described above, are far more likely to intertwine with the "real world," often mirroring it, sometimes affecting it. In recent years, some of the popular virtual worlds, especially Second Life, are growing to accommodate a user group larger in population than the following of even the most popular games. The next two sections of this chapter go into greater depth about specific library initiatives and involvement in virtual worlds, and especially Second Life. 


\section{PART II: BY, FOR AND ABOUT VIRTUAL WORLDS: NEW INITIATIVES FOR A NEW SPACE}

\section{Info Island}

Virtual Worlds have many cultural parallels with physical spaces. Second Life users, for example, can buy real estate, build structures to call their own, and interact with other users in marketplaces in which they can also buy, build and manage. Librarians can help answer questions they may have about using Second Life, or about the resources available in the virtual space. Libraries have traditionally been the place to help users with research about their culture and environment, and librarians have decided that users in virtual spaces should have access to virtual librarians to help answer their questions. To this end, librarians developed Info Island. Alliance Library system (ALS) (http://www.alliancelibrarysystem.com/), a multitype library system in Illinois, led most of the initial development in April 2006. Bell, Pope, Peters and Galik (2007) describe the origins of Info Island in an article in Online:

In April 2006, Alliance started a library in a small rented building in Second Life to investigate library services in the virtual world. Immediately, Alliance was approached by a number of other partners to provide library services and to work with organizations to develop customized resources for specific educational programs. As of March 2007, the Second Life Library, now called the Info Archipelago, has 17 islands (large amounts of space), 10 of which are library islands. The other islands are library partners with which we collaborate in events and projects. The Second Life Library is in the process of building a Renaissance Island where users can take part in historical role-playing, participate in costume, or just observe. (Bell, et al., p. 2)

ALS originally sought to bring library services to non-traditional library users in SL, but they soon found that SL users have unique informational needs and that librarians are drawn to SL for professional development purposes. ALS has also paved the way for consumer health information on SL, creating the Second Life Medical Library, the Consumer Health Library and the Project Virtual Hospital on InfoIsland and was awarded a $\$ 40,000$ grant by the National Library of Medicine/ Greater Midwest Region to continue this work in partnership with the University of Illinois Library of the Health Sciences-Peoria, Central Medical Library, Unversity Medical Center Groningen (UMCG) in the Netherlands, and TAP Information Services. This service is of paramount importance since roughly 85 million Americans turn to "Dr. Google" to find answers to their personal health questions and three quarters of those users fail to check the source or date of the information that they are accessing.

Second Life allows for careful analysis of information seeking behaviors and since there is often a chat transcript of transactions in SL, this is potentially fertile ground for information researchers. In terms of collaboration and networking, key information seeking behaviors, SL performs as well or better than a real world or collaborative software program such as a Wiki or Google Docs: better than real world because geography is not a factor and better than collaborative software programs because there is an element of play and exploration to using a virtual environment that may be significantly different than trying out other programs. Moreover, there is an element of role play that is also absent in those other programs and that could make approaching an "Information Desk" with a question less intimidating. Other aspects that come into play in information seeking in both real and virtual environments, such as serendipity, work about the same way. Again, users in SL may feel more comfortable about asking a complete stranger for assistance, especially if they are not the established "librarian". MUVEs like SL are unparalleled in creating a safe "sandbox" area where users can try out new concepts, experiment with 3-D "blue sky" modeling and more, even if 
it has mostly been used for leisure activities until now. The potential for meeting for large-scale programs like climate change summits is largely unexplored, but the possibility of bringing together leaders in this area without the added impact of travel and its accompanying problems is huge.

Alliance's page(http://infoisland.org/groups/) lists a number of library-related groups that meet on the Info Archipelago. Reading clubs, specific public and academic libraries and reading groups are all mentioned. One group, the Archivists of Second Life, is an interesting initiative because archival projects can both extend work anchored in real-life libraries, and exist to archive Second Life resources. Preserving, organizing and maintaining the culture and history of a virtual world is a challenging endeavour and leads to the next part of this section: The Preserving Virtual Worlds Project.

\section{Preserving Virtual Worlds}

The National Digital Information Infrastructure and Preservation Program, a Library of Congress Initiative whose mission is "to develop a national strategy to collect, preserve and make available significant digital content, especially information that is created in digital form only, for current and future generations" (http://www.digitalpreservation.gov/library/) recently awarded a multimillion dollar collaborative grant to fund an initiative led by the University of Illinois at Urbana-Champaign (UIUC) to explore the preservation of virtual worlds.

The Preserving Virtual Worlds Project (http:// pvw.illinois.edu/pvw/) is a collaborative effort between the University of Illinois at UrbanaChampaign, the University of Maryland, Stamford University, Rochester Institute of Technology and Linden Lab. Their Web site describes their goals: "The Preserving Virtual Worlds project will explore methods for preserving digital games and interactive fiction. Major activities will include developing basic standards for metadata and content representation and conducting a series of archiving case studies for early video games, electronic literature and Second Life, an interactive multiplayer game." A recent article in The Atlantic by Clay Risen (2010) quotes one of the preservation project leaders, "The cultural history of our world is wrapped up in digital worlds, and in the future, if people want to understand our culture, they're going to need documents and information," says Henry Lowood, who leads the preservation effort at Stanford. "We're in a position to do something about that for these synthetic worlds. (para. 5)" Clay describes the difficulty of preserving virtual culture (worlds, games, etc) that are trapped on obsolete hardware like older game cartridges and floppy disks (para. 6).

Others are creating SL spaces for digital preservation as well, for example, http://ils.unc. edu/SLEC/. As virtual worlds become increasingly integrated in our global society, libraries' presence in these worlds lends credibility to their importance in education, and their importance as a cultural artifact.

\section{Mystery Manor}

Mystery Manor is a Victorian house rendered in 3D on Alliance Library System's Info Island. Spooky, Gothic houses that the player explores have long been a conceit of videogames, starting with Mystery House, an adventure computer game released in 1980 for the Apple II and produced by On-Line Systems (http://en.wikipedia.org/ wiki/Mystery_House). Librarians on Info Island, like Lundy (2007), took this concept one step further by incorporating Reader's Advisory tips into gallery areas so that exploring players could learn to love mysteries, or, if already fans of the genre, embrace new titles that may have been previously unknown to them. Since the galleries are virtual, updating them is less time-consuming than updating a physical display and librarians are not limited by space constraints if they want to add additional titles or info, such as biogra- 
phies of authors (para. 3). Mystery Manor book discussions and links to Mystery Manor from the SL search function both serve to draw visitors to the galleries. Library staff are able to update via Google Docs or delicious (http://delicious.com/, formerly del.icio.us) links. Mystery Manor is a good example of using a virtual world to update a library service that has traditionally been offered in the real world, in the form of Reader's Advisory, Read a Likes and displays so that added value is provided at little or no cost to the library.

\section{Virtual World "Collections and Acquisitions"}

What, exactly, does a library in a virtual world "collect"? Collection development, which in a bricks and mortar library consists of myriad tasks from creating collection development policies to cataloging materials, to weeding, takes on new meaning, with a plethora of new tasks. Weeding can be done with the click of a button to delete an unwanted object, the trouble and expense of waste and recycling are spared. Collection development consists more of curating digital art or photographs and foregoes things like acquisitions, processing, binding, etc. These are obviously great cost savers, but patrons who are accustomed to a physical object and tactile experience may feel like they are missing out if the collection is solely virtual. Thusly, it makes sense that MUVE library exhibits be created in order to support physical library collections, rather than usurp them. The best examples of virtual world "collections" augment what physical libraries already offer, or spin them in a new way. For example, Info Island's Virtual World Landmark Center converts the reference desk concept into a travel agency of sorts, directing patrons to places to dance, places off the beaten path and other destinations similar to what might be found in the travel section of your local library, but with the added caveat of being able to whisk you away there for a virtual vacation instantly (http://infoisland.org/2010/03/02/virtual-worldlandmark-center/).

According to Ashford (2009), some pioneering Library schools, including the University of Illinois at Urbana-Champaign's Graduate School of Library and Information Science (UIUC's GSLIS) have brought in their students to better introduce academic librarians to virtual worlds (para. 1). Web tools like Sloog.org enable in-world librarians to bookmark favorite places and avatars, just as a real-world librarian might use a service like delicious to better serve his or her patrons. These web tools allow librarians to create collections of online resources they can later turn into a more attractive guide, or even share as-is, possibly as an RSS feed (para. 7).

Exposing library subscriptions to users in virtual worlds is a future direction for librarians. Currently, electronic databases can be accessed by links on library websites. Users from home often need to authenticate, often through a proxy server, to gain access to resources. Possibly one day in the future virtual worlds like Second Life could have the budget for a subscription to resources for Second Life users, that they can access through an object or other, non web-based interface on the virtual world. Even now, however, before this exists, there are still so many information resources on Second Life, it it crucial for users to be able to sift through it all, which leads to the next section on Information Literacy.

\section{Information Literacy}

According to The Association of College and Research Libraries (ACRL) (2000), "Information literacy is a set of abilities requiring individuals to 'recognize when information is needed and have the ability to locate, evaluate, and use effectively the needed information (p. 2)." Users need to know how to navigate the information landscape of virtual worlds. For example, how can a user know that another avatar is who s/he says they are, representing the organization s/he 
claims an association with? They need to know how to locate information in virtual worlds, and information about virtual worlds. Thus, information literacy instruction is about teaching new information literacy skills that are relevant to this new information platform. It is also possible to virtual classrooms as meeting places to teach traditional, and often more abstract information literacy skills that are transferable to multiple information platforms.

Second Life represents a real value added in terms of promoting Information Literacy, partly from the aspect of being where the users are. Students in particular have expressed interest in having their information needs met in one centralized location, as shown through the push for information centers in places where students do their social networking, like on Facebook, and through the push for centralized physical spaces, often called Information Commons, in library buildings. Librarians in far-flung places can man desks in accordance with their schedules and locations in SL, and there is currently a reference desk in Second Life for answering questions on InfoIsland. There is a real need for this service since Information Literacy is especially important in an online world where tons of information is generated and nobody is helping users critically evaluate the information. Moreover, Information Literacy in virtual worlds is crucial because there is so much advertising and commercialism there, and organizations and vendors are all centrally located in the same spot and vying for the same eyeballs. As Goodstein (2008) notes in Library Journal on marketing to teens, teens are "multitaskers" and they want their social networking to be part and parcel of their information seeking (para. 2). As an aside, Teen Second Life (TSL) does not allow advertising, so this is less of a concern there, however, purchasing an island still requires real currency and financial literacy skills. Just as it is important for librarians to be available in the real world to help patrons navigate governmental and other resources, it is equally important for librar- ians to be available inworld to help guide users in the virtual environment and beyond.

Assessment of information literacy skills is made easier in Second Life by the ease of recording transactions. When librarians assist in a virtual world with an immersive, interactive presence, or create subject guides and assist with Virtual World Information Literacy (VWIL) for new users, those interactions are recorded in chat logs, which could later be used for library science research. Reference statistics are one way to monitor VWIL success, but measuring understanding of technology, comfort in inworld environments and other VWIL skills can be more difficult. Regardless, as libraries push to extend their services into Second Life (as is described in the next section of this chapter), it is crucial to have assessment data that supports the value of the service.

\section{PART III: EXTENDING LIBRARY SPACES INTO VIRTUAL WORLDS: REINVENTING "LOCAL"}

Libraries serve communities. Their funding comes from state and local government, and some federal funding, such as the Library Services and Technology Act (LSTA). Therefore, a proposal that seeks to create a library in a virtual world needs to have a measurable impact on the community that library serves. Marketing a library's virtual space using traditional forms of advertisement is likely to be costly and unlikely to attract current library users, who tend to be the constituents of the local government funding the library, and thus a target population. Virtual communities work best in terms of "tribes" where like-minded individuals can unite around shared interests. This unity around subject matters rather than locale is somewhat unusual for public libraries, which tend to be "neighborhood libraries." For academic libraries, also, the targeted population tends to be the campus community, as opposed to everyone in a virtual world who might be 
interested in a particular topic. However, if the library has a physical exhibition they can augment by creating a virtual exhibition in a MUVE, they are likely to attract those interested in the subject matter and may even draw people to the physical exhibition, whether those individuals are residents of the community or tourists. Exhibits can reach out by extending community information or college-campus archival collections, to users in virtual worlds. Online exhibitions should not be treated as "the-same-as-the-physical-exhibitiononly-with-digital-images" but should embrace the unique aspects of virtual worlds that allow for modeling, interactions between avatars, etc.

In Tribes: We Need You to Lead Us, Seth Godin (2008) writes, "Marketing is the act of telling stories about the things we make -- stories that sell and stories that spread." (p. 15) Stories are the lifeblood of library funding through testimonials, annual reports, and word-of-mouth marketing, the same is true for funding and maintaining a library presence on a MUVE. Since location is not a factor, it is more important than ever to unite visitors through a shared community or interest. Libraries in SL should create spaces around concepts that draw people to them and encourage them to connect with one another. Marketing to a specific community in SL is much easier than doing so in real life because creating a tailor-made space or collection does not require the level of funding that a comparable effort in reality would. Tapping into social networking tools like Twitter and Facebook can help drive users to these MUVE spaces, or to the brick and mortar building that houses the library, without limiting the pool of interest to those in the immediate locality. These tribes can be fiercely loyal; don't assume that MUVE users are any less concerned about the other members of their community than a real-life community member would be. For example, bereavement in online communities is a recognized phenomenon with groups for support and counseling, although it has not yet been studied extensively. Cognitive anthropologists Jean Lave and Etienne Wenger, have termed situated learning environments Communities of Practice (CoPs), a frequently used phrase in academic library settings among library professionals. More recently, the misnomer Virtual Community of Practice (VCoP) has come about, ostensibly to refer to MUVEs and other online communities. In Seth Godin's Tribes, the theme of the book is something along the lines of "we are all leaders." In the article "The Success of Virtual Communities of Practice: The Leadership Factor," authors Bourhis, Dubé and Jacob look at how knowledge management and leadership in these communities affects their success. Bourhis et al. (2005) write, "These [leaders] ended up in this important position because a member of the organization's management team or the sponsor had decided that they had the right set of abilities and should be selected and given the resources (often time) that were needed to do their work well." (p. 33). That is, the online community leaders who were the most successful were also the ones who positioned themselves as leaders and whose members maintained their feeling of ownership. This is consistent with leadership theories in the real world, as well.

In Godin's newer book, Linchpin (2010), he defines a linchpin as the thing you can't live without and says that many organizations are stuck in the post-factory world of assembly line culture. The authors of this chapter would argue that MUVEs like SL attract and support "linchpins" by giving them access to like-minded people and fewer or different constraints on what they are able to do and how they are able to act than they are likely to find in their home or work lives. Education is becoming a linchpin in that more schools are becoming virtual $(60 \%$ in 2006$)$ and sites like You Tube EDU (http://www.youtube. com/education? $\mathrm{b}=400)$ and iTunes University (http://www.apple.com/support/itunes_u/) are manifestations of that trend.

One example of a MUVE that has sought out a specific audience successfully is Teen SL. The age constraints of Teen SL mean that the visitors 
to Teen SL share their age group in common, even if their interests are otherwise diverse and far-flung. As a result, Teen SL has been trying to create ways for educator and librarians to introduce projects to the teens that frequent SL. Campus: TSL is a project that provides middle school and secondary educators and students aged 13-17 with a dedicated parcel of land for the duration of a class. Another example of a teen site using a MUVE for educational purposes is Simteach.com, "a place for university instructional designers, faculty and administrators to find information and to share their own experiences designing, teaching and administering classes in immersive environments." Interest in MUVEs dovetails nicely with interest in machinima, the use of 3-D graphics rendering engines to produce animations, and is an example of a topic that may be taught more easily in a virtual environment than in a classroom. Similarly, the nonprofit Globalkids.org has an online leadership program that meets in Teen SL. The MacArthur Spotlight blog had this to say about their work: "High school kids from Washington, D.C., involved in the Witnessing History project, certainly appeared motivated by the immersive aspects of working in the virtual space of Teen Second Life. The project was produced in conjunction with Global Kids and the U.S. Holocaust Memorial Museum. It was there that a handful of students curated an exhibit where visitors assumed the role of reporters-replete with fedoras and notepads-to learn how bystanders reacted to the horrors of the 1938 Night of Broken Glass pogrom at the outset of the Holocaust."'(http://spotlight.macfound.org/ btr/entry/teens_virtual_worlds_learn_civic_lessons/) In other words, this project was similar to many teen educational endeavors that take teens on field trips to their local libraries or museums, with the added facet of teens doing the work of curator rather than just passively observing the exhibit. Moreover, for the one-time $\$ 9.95$ fee (and up), teens can learn what it's like to start a business buying and selling things or what it is like to buy real estate. These are life lessons that might be difficult for the average teen to cultivate in real life.

Real world cultural institutions could benefit from reaching out to new audiences via SL. Recently, The New York Public Library (NYPL) ventured into online exhibits with their Candide 2.0 interactive reading experiment (http://nypl. org/blog/2010/02/17/candide-20) which mirrors their exhibit in the real world in the Wachenheim Gallery at the Stephen A. Schwarzman Building in New York City. One might imagine that such an online exhibit would work nicely with a sister exhibit in a virtual world like Second Life, highlighting the real world treasures of the NYPL and perhaps driving tourism to the real-world exhibit in the same way that the interactive online exhibit does. Moreover, live author talks or interviews that are by necessity limited in terms of audience size and that must take place at a specific time and locality due to an author's busy schedule can be recorded and made available through a virtual repository, or can be contributed to while they are ongoing by opening up the conversation to virtual world chats, even if the author does not choose to do a "live" discussion in the virtual world through their avatar.

Many universities have set up private islands of their own, for a list: http://www.simteach.com/ wiki/index.php?title=Second_Life:_Universities_and_Private_Islands. Moreover, many K-12 and higher education institutions have SL virtual campuses, including The Open University, Harvard, Texas State, and Stanford. The Open University (OU) is the largest university in the United Kingdom. According to OU's Linden Research Inc. (2009) SL case study, "In one 7-day period the OU recorded 130 unique visitors spending a combined total of 216 hours in their virtual campus, Open Life (p. 1)." Colleges and universities have long advised students to spend at least five hours studying for every hour spent in class. If students can spend more time on a virtual campus or in a virtual library by not needing to commute to find the resources that they need in a far off 
physical building, then they are that much closer to accomplishing their goals. As the profile of a "typical" student is changing and more students are juggling family, work and student life, this extra bit of flexibility is key. Other tricks that colleges and universities have long employed include changing the setting. That is, on a beautiful day, instead of trying to wrest students' attention away from looking out the window, professors sometimes move their classes outside or to a more aesthetically pleasing location. In SL, the ability to do this is unhindered by the limitations of a physical campus. Class can take place on a tropical island, or even a pirate ship. Presumably, professors would want to choose a setting that corresponds to their topic. Just as colleges and universities employ Resident Assistants (RAs) to help acclimate freshmen to their surroundings, SL virtual campuses can designate users to assist "newbies" in finding their way around the virtual world. Academic libraries can emulate the successes of SL campuses and work with their faculty to create spaces that are consistent, nurturing and that share best practices.

Nonprofits and medical education centers have also experimented with creating community via MUVEs. TechSoup has set up a nonprofit archipelago in SL called Nonprofit Commons (http:// www.nonprofitcommons.org/). Similarin practice to the mission of many libraries, the Nonprofit Commons seeks to provide a space where nonprofits can meet to entertain, educate and assist in a community of practice. In their article on using SL for medical education Wiecha, Hayden et al. (2010) write, "the greater sense of 'presence' in a virtual world positively influences group process and cohesiveness, as well as engagement and attention (para. 9)". Librarians and health and medical specialists alike have enjoyed the ease of creating displays and information kiosks in SL. Conducting outreach to the public with slideshows, web links and videos is quite easy to do within these venues, as both of these professions rely heavily on outreach.
Nonprofits, educational institutions and medical education institutions also share a key interest in public programming. As a result, when establishing a SL presence, just like when establishing an online presence, basic information about the real world library may still be of interest to users, such as library hours. According to Sauers (2007), taking the processing power of your public PCs under consideration is also very important. Ideally, a cable or DSL connection, a 1.6 GHz Pentium processor or similar, $512 \mathrm{MB}$ of available memory and a suitable graphics card will ensure that your users have a productive experience (slide 11). Wiecha, Hayden et al. also note "the learning curve for navigation and interaction is steep, and the possibilities for technical problems and failures during the actual event are numerous. Many corporate or university firewalls do not allow access to public virtual worlds like Second Life (para. 10)."

Communities are also springing up in SL in response to both the limitations and the possibilities that the MUVE technology encompasses. Virtual Ability, Inc., the owners of HealthInfo island, have made it their mission to help disabled users to get the specialized hardware and software they need so that they can have access to virtual worlds like SL. Physical libraries have long tried to make their services accessible to all users, sometimes through the phyiscal structure of the building and sometimes by providing software such as MAGic screen magnification software or JAWS multi-lingual speech synthesizer so that Internet resources can be accessed by users with vision or hearing impairments. The benefits of virtual mobility for the differently abled are clear, as are the benefits to having library resources housed in a computer rather than in a bricks and mortar building. Since the experience of interacting in a virtual world is so different from interacting through the Internet, there are real cognitive benefits to the differently abled using SL and librarians should be there to help them, and others, navigate this new space.

In the early days of the Internet, Web Site Developers initially tried to create individual 
Web pages that were tailored to specific reasons for going to that page. Today, partly due to search engines, Web pages tend to address a multitude of reasons for visiting that page and ways to redirect users to what they are trying to accomplish on the site. Similarly, many early SL presences may seem one-note. As SL grows and evolves the amount that visitors can do on any one island should evolve as well, partly under their own curation and cultivation.

To be sure, SL and othe MUVEs offer a lot of the benefits of the real world as well, one of those benefits being library access and library professional development opportunities. While some may see in-person conference interactions as a waste of money and as merely an opportunity for free snacks for those attending, conferences excel at being ways for attendees to report back on what they've learned, including tips and tricks from interactions with other attendees and information from vendors. Online conferences can recreate those same behaviors, plus be accessible to those who should attend but may not be able to due to personal commitments: health, family, etc. Even the much-maligned snack table serves a purpose. Resource sharing is a way to cement interactions between humans, and while the opportunity for food sharing in MUVEs is lost, there are many other objects that participants can share to help build community and encourage conversation. Similarly, while face-to-face interaction is hard to replicate in a chat room, chat rooms still go a long way towards building relationships, and those relationships may even go on to be cemented at a real-world meeting or conference.

\section{PART IV: FUTURE RESEARCH DIRECTIONS}

As of the writing of this chapter, there may be funding available, especially from institutions like the National Science Foundation and the Department of Education, to support research into how video games can be used in education. According the University of Michigan's News Service (2009), the NSF has supported projects looking at how trends spread in SL, as examined by social scientists at the University of Michigan ("Second Life Data"). According to Seupersad (2010), the U.S Department of Education has used SL to enhance traditional curriculums in $\mathrm{K}-12$ schools. There is even a SL version of the U.S. Congress so that Second Life residents can be kept abreast of policy changes on capitol hill. Considering the newness of virtual worlds, we can assume that these pioneering grants are just the beginning and that as virtual worlds evolve, so will the methodologies and topics studied and the ways in which they are used in classrooms and libraries. While World of Warcraft and similar games have inspired community, few have held the interest of the government and other organizations that SL has. SL bucks the definition of "game" since there is no leveling up or finishing, and the rewards system has more to do with social networking (ratings, statistics, personal gratification) than with the standard gaming rewards (ranking, advancing, etc.)Visually, the similarity to The Sims is striking, but that's where the similarity ends. The research on the effect and benefits of online communities and leadership in online communities is just beginning. Likewise, a satisfactory way for teacher evaluation of student work in online communities has yet to be fully developed.

For busy professionals and students, virtual worlds offer a way for them to fit communicating with their "tribe" and modeling ideas into their schedules. One might questions why virtual worlds are an improvement over instant messaging or other collaborative software, especially given the steep learning curve and the time that they take to use. Virtual worlds are not ideal for all information transactions, but there are several benefits. Having an avatar contributes to a sense of self-representation and presence that is lacking in more traditional forms of collaboration, such as conference calls. Testing the receptivity of a 
small group to virtual worlds might be a good way to start. That way, the group leader can control technical considerations and instead focus on what participants do, would like to do and foresee as the future of information transactions in MUVEs.

As virtual worlds become easier to use and future generations gain increased competency in them, they are likely to become a larger part of both work and leisure time. Toro-Troconis (2009) surmises that as 3-Dinterfaces become ubiquitous, we may see MUVEs replacing Web browsers ( $p$. 8). Also, that standards will emerge much as they have for Web browsers and that porting objects or avatars from disparate MUVEs will become de rigeur. Though MUVEs are not games in the traditional sense, Toro-Troconis quotes Gee (2003), saying that good games have clear goals and "explicit information both on-demand and just in time when the learner needs it". While SL does not have a goal, per se, the users are usually motivated by their goals to come to SL, and SL satisfies the second objective of creating immersive environments that provide information on-demand. Toro-Troconis et al also note, "It is very unlikely e-learning teams in further and higher education institutions will have learning technologists with expertise in game design, which makes the process of designing game-based learning activities in MUVEs more challenging and expensive. Game designers may be brought into the team from external providers. However, this may increase development costs as well as making the development process longer until the game designers become acquainted with the culture of the educational institution and the learning outcomes of the game-based learning activity to be produced."

\section{CONCLUSION}

With a retention rate of just $10 \%$ for SL among US users in 2010, SL may not turn out to be the technology gold rush that many were counting on back in 2007. Linden Labs reported 1,382,003 users logging in within the last 60 days as of Tuesday, June 22, 2010, despite the layoffs of 30\% of their staff at the beginning of the month. The restructuring was reportedly a response to their low retention rate. Despite SL being a free community, many users join but then never become active users. SL is working to fix this with new welcome pages and new orientation and trainings, but this figure hasn't improved much. However, there were still over 15 million residents as of August 2008 and there is still much to be gleaned from the interest that educational, nonprofit and governmental institutions have shown in this burgeoning 3-D online space. According to Schaffhauser (2008), at Huntington Junior College in West Virginia, a mash-up of SL and the Moodle Open Source Class management system (nicknamed Sloodle) led to a $16 \%$ increase in their distance learning program's retention (para. 4). Competitors like Entropia Universe and Disney's purchase of Club Penguin for $\$ 350$ million suggest that corporate interest in MUVEs is also still alive and well. Competitor Eve Online (www.eveonline.com/, now dubbed Dominion) limits the scope of the online community to science-fiction but retains the ability to form alliances, buy and trade that SL has, for a starting fee of $\$ 9.95$ a month, but it is a massively multiplayer online role-playing game (MMORG) in the strictest sense. Critics have suggested that SL and MUVEs like it are aimless, similar statements could be made about libraries as well, yet time has proven that libraries are a fertile ground for personal growth and networking and we think that MUVEs have not yet reached their full potential as spaces for learning and community.

As Stimpson notes in her description of being "the only person around" when visiting some less popular SL locations, the implementation and outreach around these sites has the potential to turn them into virtual ghost towns, or "ghost sims" as Stimpson calls them. In fact, SL is far from being truly deserted, since not every resident 
is in-world all the time, and when they are they tend to spread out since teleportation is so easy to do and there's no need to wait in line like there is in real life. However, the question remains, how do we build community centered spaces in SL? Second Life libraries fulfill the requirements of being community centered spaces where access to information is readily available, without the physical demands of providing a public space, yet the person who is implementing the SL presence must be acutely aware of who their audience is and what they will be doing there, and that both of those things are readily apparent from virtual signage, etc. There are many other challenges librarians face when migrating services to the virtual arena. For example, virtual worlds are often very graphics intensive and require updated and sometimes expensive hardware, as well as high bandwidth, fast Internet connections, both of which may not be available system-wise in a large library. Additionally, some see virtual worlds as "games" and while gaming is gaining popularity as an educational tool, the justification for spending resources on a non-essential service may not come easily to all librarians. Despite this view, Second Life does promote educational gains in the areas of the use of Lindens (the virtual currency of Second Life) and by encouraging users to script or program virtual 3D objects, buildings and clothing using LSL (Linden Scripting Language), the programming language of SL, not to mention as a springboard for social networking. The introduction of Teen Second Life addresses many concerns that some may have about creating suitable chat spaces for young people. In 2009, SL introduced age verification for adult users, to mixed reviews, showing that it is not yet a perfect science. This just goes to show how Second Life online spaces, like real world spaces, can be a places where unforeseen interactions play out in unexpected ways, i.e. money exchanges going awry, etc. Second Life also has a steep learning curve, especially on slow and undependable hardware, and even for experienced game play- ers, which may be too much of a stumbling block for users on the wrong side of the digital divide.

\section{REFERENCES}

Ashford, R. (2009, April 9). Should academic librarians assist in virtual worlds? Librarian By Design. Retrieved April 9, 2010 from http:// librarianbydesign.blogspot.com/2009/04/shouldacademic-librarians-assist-in.html

Association of College and Research Libraries (ACRL). (2000, January 18). Information literacy competency standards for higher education. Retrieved April 8, 2010, from http://www.ala.org/ ala/mgrps/divs/acrl/standards/informationliteracycompetency.cfm

Bell, L., \& Trueman, R. B. (2008). Virtual worlds, real libraries: Librarians and educators in second life and other multi-user virtual environments. Medford, NJ: Information Today.

Bourhis, A., Dubé, L., \& Jacob, R. (2005). The success of virtual communities of practice: The leadership factor. Electronic Journal of Knowledge Management, 3(1), 23-34. Retrieved April 8, 2010, from http://www.ejkm.com/volume-3/ v3i1/v3-i1-art3-bourhis.pdf

Community Virtual Library. (2010, March 2). Virtual world landmark center. Retrieved April 9, 2010, from http://infoisland.org/2010/03/02/ virtual-world-landmark-center/

Czarnecki, K. (2008). Virtual environments and K-12 education. MultiMedia \& Internet@ Schools, 15(4), 14-17. Retrieved November 10, 2009 from http://search.ebscohost.com/login. aspx?direct $=$ true $\&$ AuthType $=$ cookie,ip,url,cpid $\&$ custid $=$ nypl $\& \mathrm{db}=$ aph $\& A N=33181081 \&$ site $=$ ehost-live.

Godin, S. (2008). Tribes: We need you to lead us. New York, NY: Portfolio. 
Goodstein, A. (2008, May 1). What would Madison Avenue do? Marketing to teens: To attract today's teens, think like a marketing pro. School Library Journal. Retrieved April 8, 2010, from http://www.schoollibraryjournal.com/article/ CA6555544.html

Greenhill, K. (2008). Do we remove all the walls? Second Life librarianship. Australian Library Journal, 57(4), 377-393. Retrieved November 10, 2009, from Academic Search Complete database from http://search.ebscohost.com/login. aspx ?direct $=$ true $\& \mathrm{db}=\mathrm{a} 9 \mathrm{~h} \& \mathrm{AN}=37251467 \&$ sit $\mathrm{e}=$ ehost-live

Life, S. Universities and Private Islands. (2009, October 22). SimTeach. In Wikipedia, the free encyclopedia. Retrieved April 9, 2010 from http://www.simteach.com/wiki/index. php?title=Second_Life:_Universities_and_Private_Islands

Linden Research, Inc. (2009). Case study: The Open University's place for us: Providing geographically dispersed students \& faculty a place to meet and learn together. Retrieved April 9, 2010, from http://secondlifegrid.net.s3.amazonaws. com/docs/Second_Life_Case_OpenU_EN.pdf

Lundy, M. (2007, September). Second Life brings new worlds to readers' advisory. Readers 'Advisor News: An E-Newsletter Published Quarterly by Libraries Unlimited. Retrieved April 9, 2010, from http://lu.com/ranews/sep2007/lundy.cfm

Montandon, M. (2009, December 2). Teens in virtual worlds learn civic lessons that are anything but dull. Spotlight on Digital Media and Learning. Retrieved April 8, 2010, from http:// spotlight.macfound.org/btr/entry/teens_virtual_ worlds_learn_civic_lessons/

Mystery House.(2010, February 27). In Wikipedia, the free encyclopedia. Retrieved April 9, 2010 from http://en.wikipedia.org/wiki/Mystery_House
Osborne, E., \& Schiller, S. Z. (2009, October). Order and creativity in virtual worlds. Journal of Virtual Worlds Research, 2(3). Retrieved April 8, 2010 from https://journals.tdl.org/jvwr/article/ view/649/515

Risen, C. (2010). Pac rat. The Atlantic. Retrieved April 8, 2010 from http://www.theatlantic.com/ magazine/archive/2010/03/pac-rat/7911/

Sauers, M. (2007). Second Life, second thoughts. Paper presented at the Internet Librarian Annual Conference, 2007. Retrieved April 9, 2010, from http://www.slideshare.net/travelinlibrarian/second-life-second-thoughts?src=related_ normal\&rel $=367275$

Schaffhauser, D. (2008, September 30). Second Life mashup helps boost distance ed retention at Huntington JC. Campus Technology. Retrieved April 8, 2010, from http://campustechnology. com/articles/2008/09/second-life-mashup-helpsboost-distance-ed-retention-at-huntington-jc. aspx?sc_lang=en

Seupersad, L. (2010). COE to receive $\$ 13.5$ million U.S. Department of Education grant. College of Education News. Retrieved April 9, 2010, from http://education.gsu.edu/main/4980.htm

Sidel, R. (2008, January 23). Cheer up, Ben. Your economy isn't as bad as this one. Wall Street Journal. Retrieved April 9, 2010, from http:// online.wsj.com/article/SB120104351064608025. html?mod=hpp_us_inside_today

Stimpson, J. (2009). Public libraries in Second Life. Library Technology Reports, 45(2), 13-20. Retrieved November 10,2009, from http://search. ebscohost.com/login.aspx?direct $=$ true $\& d b=a 9 h \&$ $\mathrm{AN}=35706783 \&$ site $=$ ehost-live

Thompson, S. (2009). On being a virtual world librarian: "Hello, can I help?" - Managing virtual volunteers. The Reference Librarian, 50(4), 422-427..doi:10.1080/02763870903130101 
Thompson, S. (2009). Pixilated problem patrons: Or, the trials of working virtual reference and what we've learned from it. The Reference Librarian, 50(3), 291-296. doi:10.1080/02763870902947125

Toro-Troconis, M., Boulos, M., \& Kamel, N. (2009, August). Musings on the state of 3-D virtual worlds for health and healthcare. Journal of Virtual Worlds Research, 2(2). Retrieved April 8,2010, from https://journals.tdl.org/jvwr/article/ view/629/496

University of Michigan News Service. (2009, July 2). Second Life data offers windows into how trends spread. Retrieved April 8, 2010, from http://www. ns.umich.edu/htdocs/releases/story.php?id=7222

University of North Carolina at Chapel Hill \& Virginia Tech. (2009, October 2). Curatorial work and learning in virtual environments. Research project conducted at the SLEC Presents: ECDL 2009 Keynote Follow-up, North Carolina, U.S. Retrieved April 9, 2010 from http://ils.unc.edu/ SLEC/

Wiecha, J., Heyden, R., Sternthal, E., \& Merialdi, M. (2010, September 1). Learning in a virtual world: Experience with using Second Life for medical education. Journal of Medical Internet Research, 12(1). Retrieved April 8, 2010 from http://www.jmir.org/2010/1/e1

\section{KEY TERMS AND DEFINITIONS}

Collection Development: For the purposes of this article, collection development refers to any virtual resources that can be accessed by a user, not only material acquisitions, although these may be referred to as well.

Communities of Practice (COPs): A term coined by cognitive anthropologists Jean Lave and Etienne Wenger, frequently referenced by academic librarians, to describe a group of people with shared interests and learning styles.

Information Literacy: The tools and behaviors that are necessary for one to successfully find and utilize relevant information.

Linchpin: From Seth Godin's book, Linchpin, the one person that a community cannot function without, or the one thing that holds an organization together.

Multi-UserVirtualEnvironments(MUVEs): Online communities that serve as virtual gathering spaces, Second Life is a frequently-referenced example in this article.

Virtual Community of Practice (VCoP): A misnomer that has arisen to apply the concept of COPs to MUVEs.

Virtual Librarianship: For the purposes of this article, we are defining a virtual librarian as a person representing any type of library, public, academic, etc., accredited or non-accredited, and serving as a steward to the resources and social networks of a virtual world, usually via some sort of formal structure such as a virtual reference desk or online gallery. 